\title{
Extension of Asphalt Pavement Life by Reduction of Temperature
}

\author{
Rajib B. Mallick ${ }^{1} \cdot{\text { Dharamveer } \operatorname{Singh}^{2} \cdot \text { A. Veeraragavan }}^{3}$
}

Received: 20 September 2015 / Accepted: 21 March 2016/Published online: 2 April 2016

(C) Springer International Publishing Switzerland 2016

\begin{abstract}
High temperatures, particularly during the summer months can lead to a number of problems for asphalt pavements—such as rutting and accelerated aging of asphalt binders, which can cause premature cracking. This paper presents the concept of using geosynthetic reinforced chip seal (GRCS) with high albedo aggregates to reduce pavement temperatures. The concept of the use of GRCS depends on two factors-the higher reflectivity of the chips or aggregates and the insulation provided by the asphalt binder saturated geosynthetic layer. Both of these factors reduce the amount of heat that is transmitted through the top part of the pavement to the deeper areas. The results of field-testing show that the benefit of reduction in temperature at the maximum temperature depth is enhanced at higher solar radiation/higher ambient temperature periods. Temperature reductions in the range of $6-12 \mathrm{C}$ can be expected in pavements in many parts of India. The utility of the approach has been investigated with the use of mechanistic empirical pavement design analysis (MEPDS). The reduction in temperature leads to a significant increase in rutting life as well as fatigue damage life, by decreasing the aging potential. Furthermore, the GRCS layer also helps in reducing the ingress of moisture from rainfall, and hence
\end{abstract}

Rajib B. Mallick

rajib@wpi.edu

Dharamveer Singh

dvsingh@ civil.iitb.ac.in

A. Veeraragavan

av@iitm.ac.in

1 CEE Department, Worcester Polytechnic Institute (WPI), 100 Institute Road, Worcester, MA 01609, USA

2 IIT Bombay, Mumbai, India

3 IIT Madras, Chennai, India prevents the onset of moisture-induced damage. The lowering of temperature also helps us avoid the need for the use of higher grade of asphalt binders. This application will be useful for both higher volume pavements (such as busy intersections with slow traffic and high temperature related rutting problems) and low volume pavements (with relatively thin sections and fatigue cracking problems).

Keywords Asphalt · Pavement - Geosynthetic - Chipseal $\cdot$ Albedo $\cdot$ Temperature

\section{Introduction}

High temperatures, particularly during the summer months can lead to a number of problems for asphalt pavementssuch as rutting and accelerated aging of asphalt binders, which can cause premature cracking [1,2]. The rutting of asphalt (hot mix asphalt, HMA) layers has been identified as one of the major causes of failure of asphalt pavements [3]. Aging of asphalt at high temperatures leads to stiffening of mixes, and premature failure by fatigue cracking. The rate of thermal oxidation of the asphalt binder in the field has been found to be doubled for every $10{ }^{\circ} \mathrm{C}$ increase in pavement temperature [4], and oxidative aging has been shown to reduce the self-healing ability of asphalt, and reduce the strain controlled fatigue life (specifically relevant for thinner pavements) of HMA pavements [5]; studies have confirmed the reduction of fatigue cracking life of aged asphalt pavements mixes [6]. Rehabilitation of such failed pavements is time consuming and costly, and repeated cycles of such failures and rehabilitation lead to a significant wastage of money, energy, time and natural resources. Instead of using thicker pavements or changing the materials of a pavement to solve this problem, an 
alternative way to address high temperature related problems in asphalt pavements could be to explore the feasibility of lowering of pavement temperatures.

The objective of this paper is to present the results of analysis of data collected over the span of 2 years from test sections that were constructed for the evaluation of a method to reduce asphalt pavement temperatures and demonstrate the utility of the use of this method through estimation of benefits for several Indian cities.

\section{Concept}

The proposed concept is of using an insulation layer and a high reflectivity (percentage or fraction of solar energy reflected compared to the total energy received, can be measured with a pyranometer, [7]) layer to reduce the amount of heat that is transmitted to asphalt pavements from solar radiation [8]. An already available technology [9], the geosynthetic reinforced chip seal (GRCS) is recommended for such an application. The concept of the use of GRCS depends on two factors-the higher reflectivity of the chips or aggregates and the insulation provided by the asphalt binder saturated geosynthetic layer. Both of these factors reduce the amount of heat that is transmitted through the top part of the pavement to the deeper areas (Fig. 1). The GRCS needs to contain a chip seal aggregate that has a higher albedo, in the range of +0.2 (compared to $<0.1$ for conventional HMA). The geosynthetic layer (polypropylene), which is typically saturated with asphalt binder (with a very low conductivity of approximately $1 \mathrm{~W} / \mathrm{m} / \mathrm{K}$ ) during laydown, has a very low conductivity (approximately $1 \mathrm{~W} / \mathrm{mK}$ ) [10] that helps in the arresting of heat flow to the layers below it.

\section{Test Section}

A test section of GRCS was constructed in the Pavement Testing facility at the University of California (UC), Davis. This GRCS was laid over an existing HMA pavement. Figure 2 shows the photo of the test section. For the GRCS

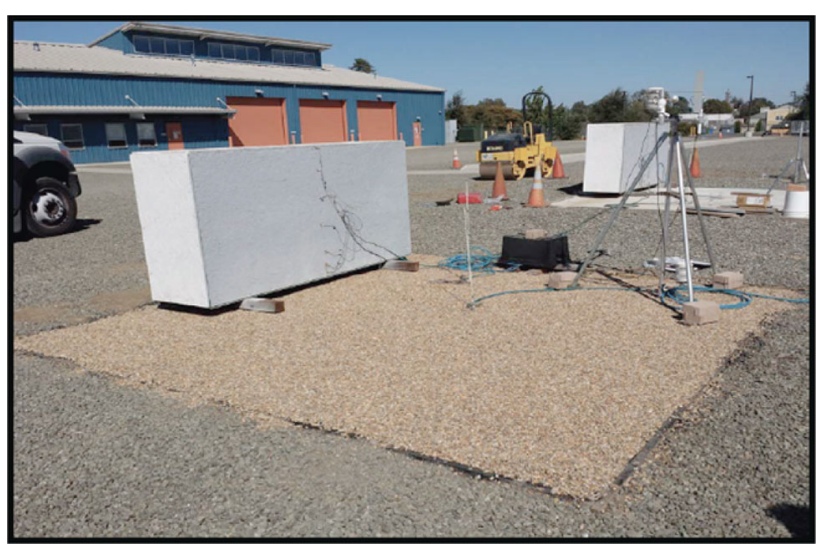

Fig. 2 Photo of the test section

a locally available PG 64-16 binder was first applied over the existing HMA surface at a rate of $1.3 \mathrm{~L}$ per square meter (residual), and it was followed by the placement and rolling of a non-woven geotextile layer. The rolling was conducted first with a rubber-coated $90-\mathrm{kg}$ hand roller, and then with a side-walk roller, after the application of sand. This was followed by the application of a polymer modified cationic rapid set emulsion at a rate of $2.7 \mathrm{~L}$ per square meter (residual), followed by the spreading of the chip seal aggregates (an alluvial gravel from central Massachusetts meeting South Dakota Type 1 chip seal gradation requirements with reflectivity of 0.24 ( $24 \%$ of solar energy reflected compared to the total energy received; for comparison, reflectivity of fresh snow is 0.9); alternative locally available aggregate with similar reflectivity is available in many locations) at a rate of $20 \mathrm{~kg} / \mathrm{sq} \mathrm{m}$. The gradation of the chip seal aggregates was as follows: 100, $55,8,3$ and 1 percent passing the 12.5, 9.5, 4.75, 2.36 and $0.075 \mathrm{~mm}$ sieve, respectively. The aggregates were rolled with the hand held roller first and then with a pickup truck with rubber tires to simulate a rubber tired roller. The hand held roller and the truck were used as this was a relatively small section-the rolling was ensured to be sufficient on the basis of the observed embedment depth of the aggregates. The section was instrumented with a weather station and thermocouples, to obtain wind speed, solar radiation,
Fig. 1 Schematic of the proposed concept of using the GRCS (not to scale)

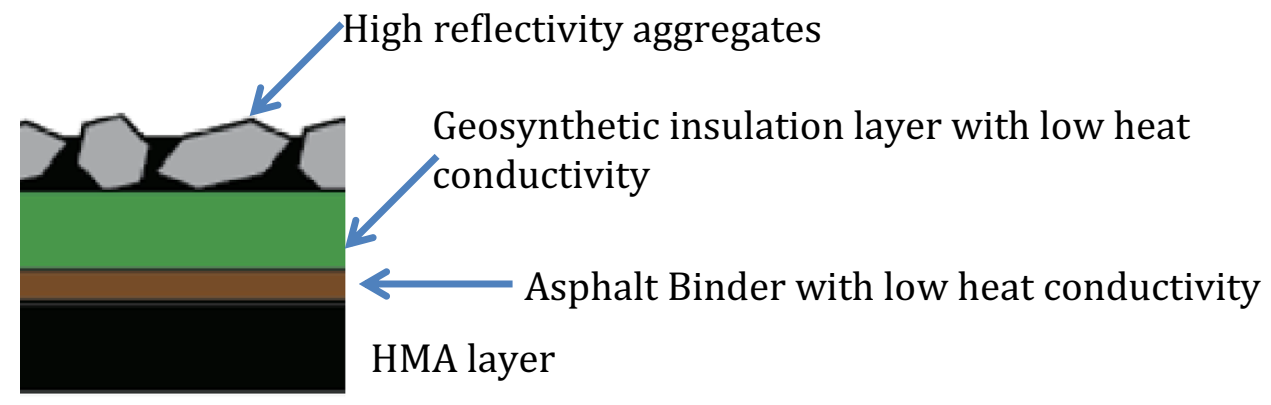


air temperature and temperatures at different depths of the pavement, as well as rainfall and humidity for a period of 1 year (September 2013-August 2014) at an interval of $30 \mathrm{~min}$.

\section{Results and Analysis}

\section{Environmental Conditions}

Figure 3 shows the air temperature data collected over 12 months for the HMA (2012-2013) and the GRCS (2013-2014) sections. The temperatures followed the same pattern in both years and they appear to be not significantly different from each other. The temperatures dipped to subzero levels for a few times and reached highs above $30{ }^{\circ} \mathrm{C}$ in September and again during the April-August period. For both years July had the highest air temperature. The three more important weather data, maximum air temperature, solar radiation and windspeed, collected over the 3 months, April-June, leading up to the hottest month, July, are summarized in Table 1. Again, these three weather parameters are found to be fairly close to each other, except windspeed in the months of April and May. The maximum air temperature ranged from 32 to $41{ }^{\circ} \mathrm{C}$, the solar radiation ranged from 1021 to $1420 \mathrm{~W} / \mathrm{m}^{2}$, while the wind speed ranged from 5.9 to $12.3 \mathrm{~m} / \mathrm{s}$. Note that the HMA section had a higher windspeed in both months, which would have contributed to lowering of pavement temperatures. The maximum temperature at a depth of $12.5 \mathrm{~mm}$ below the HMA surface is shown in Fig. 4, for these 4 months. The temperatures in the GRCS section are found to be consistently lower than that of the HMA sections.

\section{Impact of GRCS}

Note that the depth of $12.5 \mathrm{~mm}$ was selected since it has been generally used [11] for predicting the maximum temperature in asphalt pavements. In many cases, it may not be the case; for example, Table 2, data for July. In this case the field data from Davis, CA shows that the maximum temperature at $37.5 \mathrm{~mm}$ was slightly higher than the maximum temperature at $12.5 \mathrm{~mm}$. This is most likely due to the fact that temperatures at the surface and depths closer to the surface are affected more by cooling of the surface due to the convective effect of winds. Note the significantly lower surface temperature for the GRCS section, which can reduce the Urban Heat Island (UHI) effect. The use of high albedo pavements had been previously recommended (for example, by EPA, [12]) for the reduction in UHI. However, the proposed concept of using high albedo aggregates as chip seal (where a significant percentage of the aggregate surface is exposed and not embedded) is more practical because of two reasons. 1. Higher albedo achieved by coating surfaces with light/white colors can get reduced over time as colors wear off under traffic, and 2. In a conventional HMA the aggregates are coated with (black asphalt) and the higher albedo of the aggregates would be ineffective and useless. Note that the mean temperatures at all depths are lower in the GRCS section.

Based on the observation that the difference between the maximum temperatures between the HMA and the GRCS
Fig. 3 Air temperature during the data collection period for the HMA and the GRCS section

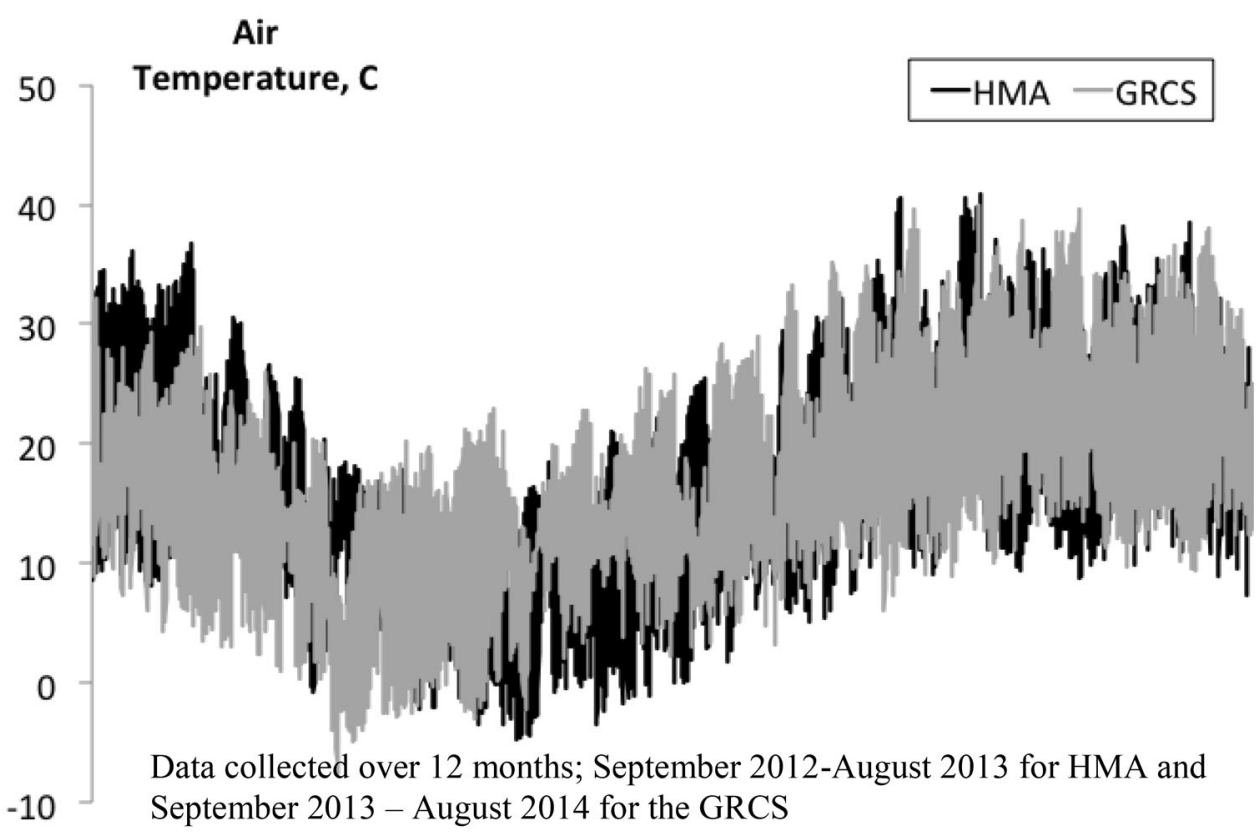


Table 1 Weather data for April to July (2013 for HMA, 2014 for GRCS)

\begin{tabular}{clll}
\hline Section & $\begin{array}{l}\text { Maximum air } \\
\text { temperature, }{ }^{\circ} \mathrm{C}\end{array}$ & $\begin{array}{l}\text { Maximum solar } \\
\text { radiation, W/m }\end{array}$ & $\begin{array}{l}\text { Maximum wind } \\
\text { speed, } \mathrm{m} / \mathrm{s}\end{array}$ \\
\hline April & & & \\
HMA & 32.2 & 1195 & 12.3 \\
GRCS & 32.5 & 1143 & 6.8 \\
May & & & \\
HMA & 33.7 & 1292 & 11.6 \\
GRCS & 35.2 & 1420 & 8.6 \\
June & & & 7.8 \\
HMA & 40.6 & 1074 & 7.1 \\
GRCS & 40.0 & 1085 & \\
July & & & 6.2 \\
HMA & 41.0 & 1021 & 5.9 \\
GRCS & 38.6 & 1261 & \\
\hline
\end{tabular}

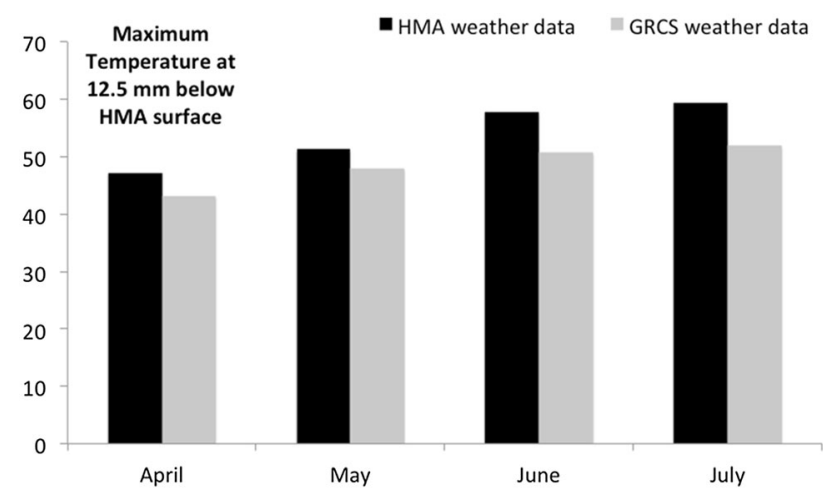

Fig. 4 Temperature at a depth of $12.5 \mathrm{~m}$ from the HMA surface

sections increases with an increase in the air temperature, a regression analysis was conducted, and the results are shown in Fig. 5. The difference has a positive regression coefficient of 0.44 with the maximum air temperature. This indicates that as the air temperature increases, the effectiveness of the GRCS in lowering the temperature also increases. This means that the benefit of temperature reduction with the GRCS is greater at higher temperatures. Physically, this can be explained as follows. The high temperature observed in pavements during summer months is a result of cumulative effect of high temperature for a number of consecutive days, due to the low conductivity of the asphalt material. A pavement which absorbs more energy will have a higher rise in temperature not only because of the absorbed energy at any point of time but also due to the cumulative energy absorbed on consecutive days, and this effect can be reduced by keeping the pavement cooler with the use of high reflectivity aggregates. Figure 6 shows plots of maximum air temperature versus the maximum temperature at a depth of $12.5 \mathrm{~mm}$ for the HMA and the GRCS sections. The GRCS plot lies below the HMA plot and also has a lower regression coefficient with the maximum air temperature. These plots can be utilized to estimate the reduction in pavement temperatures that can be achieved through the use of GRCS instead of a conventional HMA layer.

\section{Impact on pavement life}

Once it was established that the GRCS is effective in lowering the temperatures, an obvious question is, what is the impact on the pavement life? In general, the maximum pavement temperature is most significantly linked to the rutting of the asphalt (HMA) layer. A higher maximum pavement temperature can be expected to result in a faster rutting in asphalt pavements. To evaluate this concept, four cities in the eastern US, with four different maximum pavement temperatures, were utilized in mechanistic-empirical analysis [11] of an asphalt pavement. The same materials and structure were considered in all of the four cities, and the time to failure by rutting in the asphalt layer $(>0.25$ inch) was determined. The results are shown
Table 2 Maximum, minimum, and average temperatures in the month of July

\begin{tabular}{|c|c|c|c|c|c|c|c|c|c|}
\hline \multirow[t]{2}{*}{ Section } & \multicolumn{3}{|c|}{ Surface } & \multicolumn{3}{|c|}{$12.5 \mathrm{~mm}$ below HMA surface } & \multicolumn{3}{|c|}{$37.5 \mathrm{~mm}$ below the HMA surface } \\
\hline & Max. & Mean & Min. & Max. & Mean & Min. & Max. & Mean & Min. \\
\hline HMA & 71.4 & 40.1 & 18.1 & 59.5 & 35.1 & 17.9 & 60.8 & 38.0 & 21.7 \\
\hline GRCS & 58.5 & 33 & 15.0 & 51.9 & 33.8 & 20.3 & 50.8 & 34.6 & 22.6 \\
\hline \multirow[t]{2}{*}{ Section } & & & \multicolumn{7}{|c|}{$62.5 \mathrm{~mm}$ below the HMA surface } \\
\hline & & & \multicolumn{2}{|c|}{ Max. } & & \multicolumn{2}{|c|}{ Mean } & & Min. \\
\hline HMA & & & \multicolumn{2}{|c|}{59.5} & & \multicolumn{2}{|c|}{39.3} & & 24.1 \\
\hline GRCS & & & \multicolumn{2}{|c|}{49.3} & & \multicolumn{2}{|c|}{35.0} & & 24.1 \\
\hline
\end{tabular}

Max. maximum, Min. minimum 


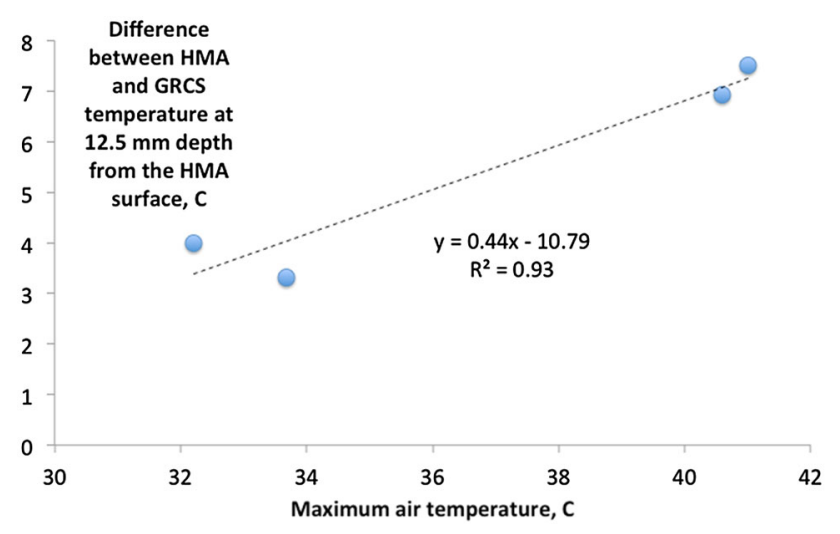

Fig. 5 Maximum air temperature versus difference in temperature

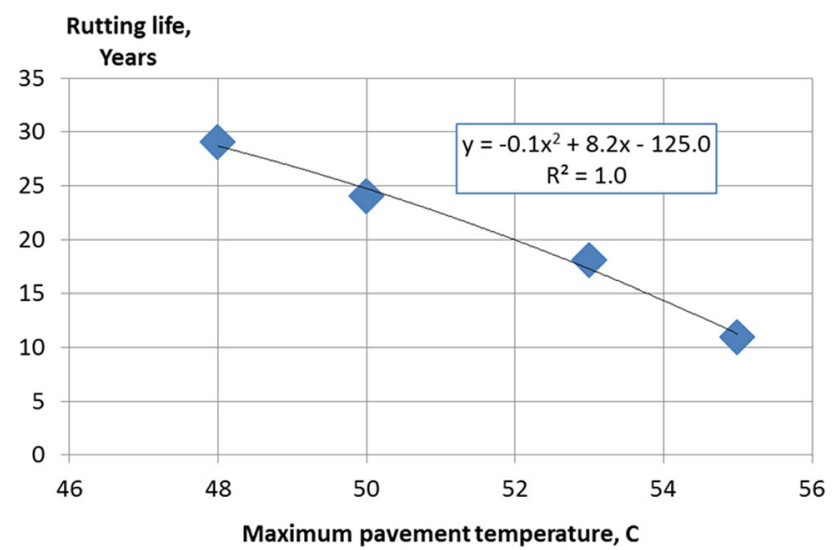

Fig. 6 Plot of maximum pavement temperature versus rutting life

graphically in Fig. 6, which was developed from Mechanistic Empirical analysis of a pavement section in four climatic regions in the US, with different maximum air temperatures.

The regression equation provides a way of relating maximum pavement temperature to rutting life of pavements. This equation was then utilized to estimate the increase in rutting life that could be achieved with the use of GRCS (over a conventional HMA) for different cities across India. The results of this analysis are summarized in Table 3. It can be seen that the increase ranges from a low $5 \%$ in Srinagar to $317 \%$ in Ahmedabad. Primarily, the increase is a function of the maximum air temperature, and Ahmedabad has a maximum air temperature of $42{ }^{\circ} \mathrm{C}$, higher than all of the other cities considered here. Very high increases over $150 \%$ can be expected in Amritsar, New Delhi and Bhopal, whereas moderately high increases can also be expected in Kolkata, Chennai, Madurai and Hyderabad. Note that in reality such large extensions (for examples pavements lasting for 76 years) will not be possible because of other factors and modes of distresses; however, the current analysis does not include the evaluation of the benefits that could be achieved through the lowering of the aging potential of the asphalt binder due to reduced temperatures (which will result in a prolonged fatigue cracking life), as well as through the reduction of ingress of moisture due to the presence of the geosynthetic layer.

Also note that there could be two limiting factors for the use of this technology. First, and the major problem could be the unavailability of aggregates with higher albedo, although, such aggregates (typically with a light color) are available in most parts of the country. Second factor could be the availability of the geosynthetic material.

\section{Discussions}

High albedo aggregates are of light color with high silica content, and are generally obtained from igneous rock, such as granite, diorite, rhyolite, and andesite [13]. A study needs to be conducted to determine the availability of such aggregates in different regions, although light colored aggregates (often used for decorative purposes) are generally found throughout India. The use of GRCS increases the cost of construction by $\$ 1-\$ 2$ per lane (12 ft) mile (US data). The cost could be higher if high albedo aggregates are not found locally. The construction of GRCS needs good quality control specifically related to the amount of asphalt binder for the tack coat and the chip seal, the selection of aggregates for the chip seal, and proper rolling of geotextile. This will also ensure the good resistance of the chip seal against the potential of shear failure; the use of polymer modified asphalt for the chip seal may be considered to ensure enhanced performance. A life cycle cost study should be conducted on a case by case basis to determine the applicability of GRCS for specific projects. In such a study, the added benefit of lowering of permeability of the surface, and hence of improving the resistance of the pavement against moisture damage, should also be considered. Note that the presence of the geosynthetic layer only, without the chip seal, can also reduce the temperature of the underlying pavement, as shown in Reference [14]; however, the presence of chip seal with high albedo aggregates was showed to produce a temperature reduction of $5{ }^{\circ} \mathrm{C}$ compared to $3{ }^{\circ} \mathrm{C}$ for the case with the geosynthetic layer only, for the case studied in small scale experiments. Furthermore, if only a geosynthetic layer is placed, it has to be surfaced with a HMA layer, which will again be subjected to high temperature and be susceptible to failure by rutting. Finally, the effect of GRCS with high albedo aggregates in winter has not been discussed in this paper. The presence of the GRCS section with high reflectivity aggregates did not seem to have any significant effect on the temperatures during the winter 
Table 3 Maximum air temperatures and corresponding pavement temperatures

\begin{tabular}{|c|c|c|c|c|c|c|}
\hline City & $\begin{array}{l}\text { Maximum air } \\
\text { temperature, }{ }^{\circ} \mathrm{C}\end{array}$ & $\begin{array}{l}\text { Maximum HMA } \\
\text { pavement temperature, }{ }^{\circ} \mathrm{C}\end{array}$ & $\begin{array}{l}\text { HMA Rutting } \\
\text { life, years }\end{array}$ & $\begin{array}{l}\text { Maximum GRCS } \\
\text { pavement temperature, }{ }^{\circ} \mathrm{C}\end{array}$ & $\begin{array}{l}\text { GRCS rutting } \\
\text { life, years }\end{array}$ & $\begin{array}{l}\text { Increase in } \\
\text { rutting life, \% }\end{array}$ \\
\hline Srinagar & 30 & 45.6 & 41.0 & 41.2 & 43.1 & 5 \\
\hline Amritsar & 40 & 57.8 & 15.0 & 52.0 & 31.0 & 107 \\
\hline New Delhi & 41 & 59.0 & 10.7 & 53.1 & 28.6 & 166 \\
\hline Bhopal & 41 & 59.0 & 10.7 & 53.1 & 28.6 & 166 \\
\hline Ahmedabad & 42 & 60.2 & 6.2 & 54.1 & 25.8 & 317 \\
\hline Kolkata & 36 & 52.9 & 29.0 & 47.7 & 38.7 & 33 \\
\hline Mumbai & 33 & 49.2 & 36.3 & 44.4 & 41.9 & 15 \\
\hline Guwahati & 32 & 48.0 & 38.2 & 43.3 & 42.6 & 11 \\
\hline Imphal & 29 & 44.4 & 42.0 & 40.1 & 43.0 & 2 \\
\hline Hyderabad & 39 & 56.6 & 18.9 & 50.9 & 33.3 & 76 \\
\hline Chennai & 37 & 54.1 & 25.9 & 48.7 & 37.1 & 43 \\
\hline Calicut & 33 & 49.2 & 36.3 & 44.4 & 41.9 & 15 \\
\hline Madurai & 38 & 55.3 & 22.6 & 49.8 & 35.3 & 57 \\
\hline
\end{tabular}

months, for the sections in UC Davis. However, the effect could be different in much cooler climatic regions, and this effect can be evaluated in a suitable study.

\section{Conclusions and Recommendations}

Based on the results of the study reported in this paper, the following conclusions can be made.

1. The use of geosynthetic reinforced chip seal (GRCS) provides a practical way to reduce asphalt pavement temperatures

2. The reduction in temperatures through the use of GRCS increases with an increase in air temperature

3. The positive regression coefficient linking maximum air temperature to maximum pavement temperature for a GRCS section is lower than that of a HMA-this means that for any given increase in the maximum air temperature, the increase in the maximum pavement temperature can be expected to be less in the GRCS section than a HMA section

4. It is estimated that the use of GRCS can extend the life (as calculated from rutting of the asphalt/HMA layer only) significantly, especially in regions where maximum air temperature is close to $40{ }^{\circ} \mathrm{C}$ or above.

5. It is recommended that trial sections be constructed in the high air temperature regions to determine the actual benefit from the use of GRCS.

Acknowledgments The authors acknowledge the opportunity to present the research work at the 3rd Conference of the Transportation Research Group of India held at Kolkata (India) from 17-20 December, 2015, that forms the basis of this article. This study would not have been possible without the help of Mr. Ryan Worsman, Mr.
Don Pellegrino of WPI, Dr. Hui Li, Dr. John Harvey, Mr. David Jones of UC Davis and Mr. Steve Thaxton of Propex Operating Company, LLC. The authors thank them for their support.

\section{References}

1. Monismith CL, Hicks RG, Finn FM, Sousa J, Harvey J, Weissman S, Deacon J, Coplantz J, Paulsen G (1994) Permanent deformation response of asphalt aggregate mixes. In: SHRP-A415, strategic highway research program, TRB, National Research Council, Washington, DC

2. Bell C (1989) Summary Report on Aging of Asphalt-Aggregate Systems SR-OSU-A-003A- 32 89-2. SHRP A-305 Report. http:// onlinepubs.trb.org/onlinepubs/shrp/SHRP-A-305.pdf. Accessed 12 Dec 2014

3. Brown ER, Cross SA (1992) A national study of rutting in hot mix asphalt (HMA) pavements. In: NCAT Report 92-5, National Center for Asphalt Technology, Auburn, Alabama

4. Dickinson EJ (1980) The hardening of middle east petroleum asphalts in pavement surfacings. J Assoc Asph Paving Technol, vol 49

5. Jung SH (2006) The effects of asphalt binder oxidation on hot mix asphalt concrete mixture rheology and fatigue performance. Texas A\&M University, Texas

6. Reed J (2010) Evaluation of the Effects of Aging on Asphalt Rubber. Masters Thesis. Arizona State University

7. American Society for Testing and Materials (2015) ASTM E1918-06 Standard test method for measuring solar reflectance of horizontal and low-sloped surfaces in the field. In: Book of Standards, Vol 04.04. ASTM International, West Conshohocken, Pennsylvania, USA

8. Mallick RB, Sakulich A, Chen B-L, Bhowmick S (2013) Insulating pavements to extend service life. In: RILEM symposium on multi-scale modeling and characterization of infrastructure materials, Stockholm, Sweden

9. Skip Brown N (2013) Geosynthetic-reinforced double chip seal tames troubled streets. Pavement Preserv J 6(3), Naylor, LLC

10. The Engineering Toolbox (2012) Thermal Conductivity of Some Common Materials and Gases. http://goo.gl/3yGXCc. Accessed 30 Dec 2012 
11. National Cooperative Highway Research Program (NCHRP) (2004) Guide for mechanistic- empirical design. Transportation Research Board, Washington, D.C., USA. http://onlinepubs.trb. org/onlinepubs/archive/mepdg/guide.htm, last accessed May 2015

12. United States Environmental Protection Agency (EPA): Reducing Urban Heat Islands: Compendium of Strategies. Cool Pavements. Available at: http://www.epa.gov/heatislands/resources/ pdf/CoolPavesCompendium.pdf; last accessed, May 2015
13. Langer W (1993) Natural aggregates of the conterminous United States. US Geological Survey Bulletin 1594. US Geological Survey, Denver, Colorado, USA.

14. Mallick RB, Sakulich A, CB Liang, Bhowmick S (2013) Cool and long-lasting pavements with geosynthetic reinforced chip sealsgreen streets, highways, and development 2013: advancing the Practice ASCE 